\title{
The Influence of Microspectroscopy on Evaluating and Analyzing Forensic Evidence
}

\author{
J A. Reffner \\ SensIR Technologies, LLC, Danbury, CT, 06810
}

The evaluation and analysis of evidence using infrared, Raman and SEM/EDX microspectroscopical methods have advanced forensic science. Forensic science deals with the interaction of science with the law and includes both criminal and civil investigations. Microspectroscopy has become a primary technology to increase the value of evidence by extending observations, enhancing documentation, providing additional information, aiding deductions and testing hypotheses.

The Law has two major divisions, criminal and civil. Criminal law deals with individual actions against established state statutes. Crimes are investigated and prosecuted by the state. The Court determines if an accused is guilty or not guilty. If guilty, the Court sets the punishment. Civil law deals with disputes between individuals. Civil actions are brought to court by private individuals or organizations against individuals or organizations. The Court rules on liability and sets the damages.

While the numerous televised episodes of crimes solved by scientific investigation excite public interest, adoption of new technologies by police laboratories is a slow and deliberate process. Light microscopy is the main technology for the trace evidence examiner. The discovery and comparison of evidence is anchored by microscopical observation. As far back as 1978, infrared microspectroscopy was introduced to laboratories examining trace evidence relevant to criminal investigations. However, it was not until the mid-1990's that this methodology was acknowledged as a necessity for all forensic laboratories. SEM/EDX has a similar history. Only after automated gunshot residue analysis was developed, did SEM/EDX systems become more than just a novelty for the larger crime labs. Now, Raman microprobes stand like a bride on the outside, waiting for her lover to carry her over the threshold. There is great potential for Raman spectroscopy to be a major methodology for forensic evidence analysis. Crime laboratories are exploring Raman microspectroscopy; while progress is slow momentum is building.

Since civil actions revolve around money, it is generally easy to justify using the latest technologies to build the preponderance of evidence needed to support or rebuke claims of liability. A drug company may defend its rights of monopoly, granted by the issuance of a patent, by filing a civil action to prevent a competitor's infringement. Tens of millions of dollars hang in the balance. Factual evidence and expert interpretation are pivotal to building this case, expense becomes secondary. Chemists, engineers, metallurgists, and other scientists are drafted in to serving as either fact or expert witnesses and to giving court testimony. Because images convey so much information and attract the attention of Judges and jurors, microscopists are a valuable resource for civil actions. If images are supported by spectral analysis, then the evidence can have increased value.

In conducting a scientific examination of evidence, the forensic scientist follows the basic tenants of the scientific method, observation, documentation, contemplation, speculation and verification. This mantra is followed from either the simple analysis of trace fiber evidence in a murder investigation, or 
investigating the polymorphic behavior of a drug substance. Microscopy and microspectroscopy are united to detect, document, evaluate and analyze evidence. The evidence must be clearly and convincingly presented to the court and analysts must be capable of validating both instrumentation and methods.

When there is violent contact between two articles, there is a transfer of materials. This is the Locard exchange principle. This is the basis for searching for trace evidence in criminal investigations. In Fig. 1, the transfer of fibers from a bulletproof vest on to the bullet is shown. The infrared spectrum of fibers found on the bullet confirms that this bullet had violent contact with a bulletproof vest.

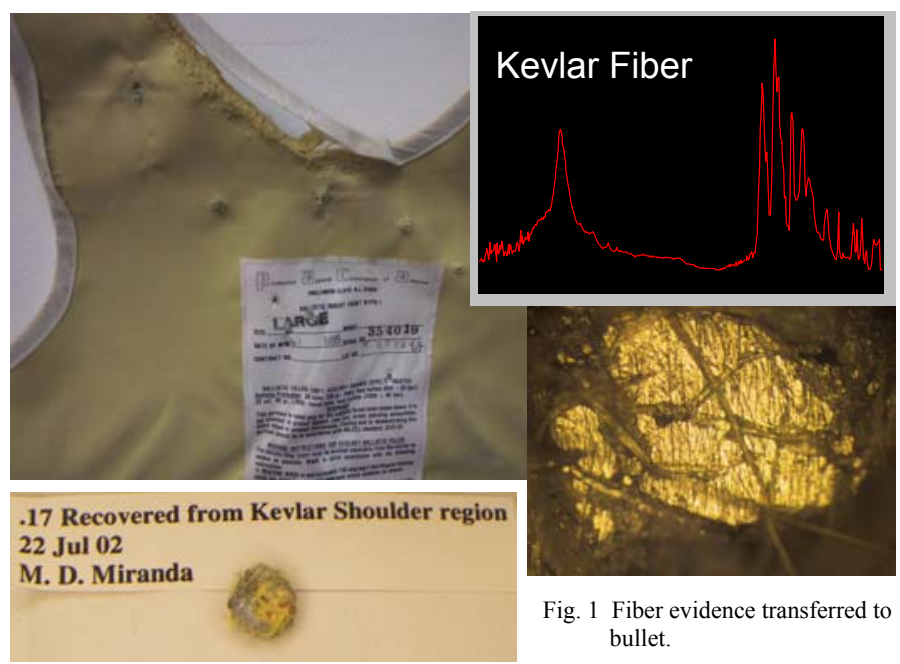

The characterization of solid drug substances is an important in regulatory proceedings, patent applications and in defending commercial drug products. Fig. 2 illustrates the polymorphic behavior of ranitidine hydrochloride. Both polymorphic forms of this drug were patented, extending the monopoly rights for three additional years.
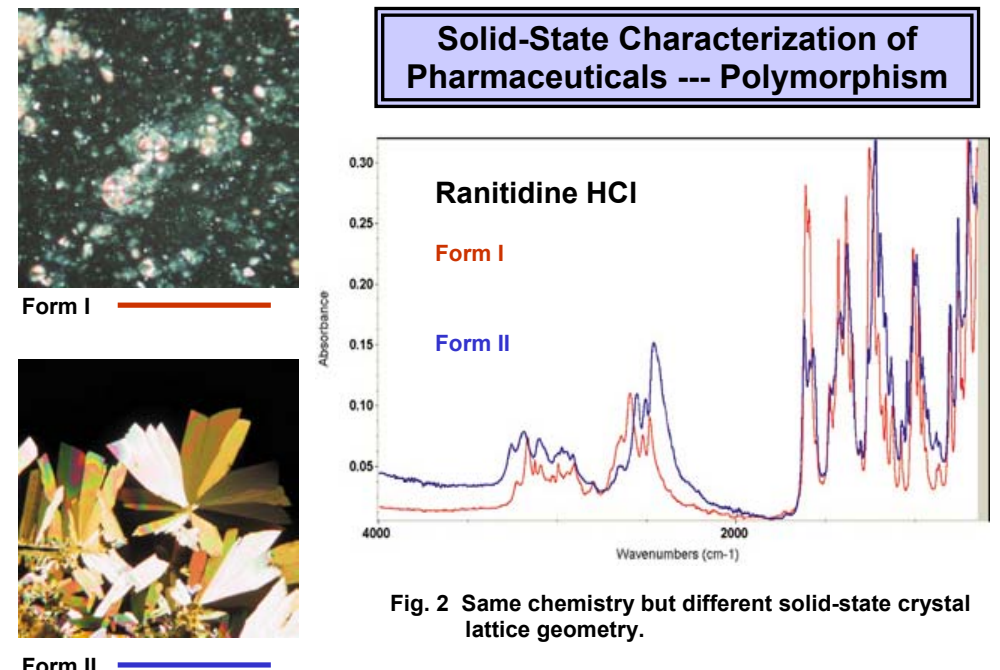

Fig. 2 Same chemistry but different solid-state crystal lattice geometry. 